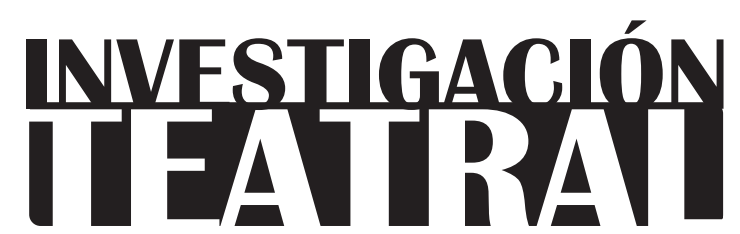

Revista de artes escénicas y performatividad

Vol. 12, Núm. 19

abril-septiembre 2021

Segunda época

ISSN impreso: $1665-8728$

ISSN electrónico: 2594-0953

Universidad Veracruzana

\title{
Cuatro cuerpos para la construcción de personajes en la danza escénica
}

Sarahí Lay Trigo*

\footnotetext{
* University of California, Santa Cruz, Estados Unidos. e-mail: sarahilaytrigo@gmail.com
}

Recibido: 17 de abril de 2020

Aceptado: 23 de noviembre de 2020

Doi: $10.25009 /$ it.v12i19.2675 


\title{
Cuatro cuerpos para la construcción de personajes en la danza escénica
}

\section{Resumen}

Construir un personaje en la danza escénica, en particular en la danza clásica, no es sólo interpretar técnicamente con el movimiento un personaje como Julieta, Odile, Giselle, Romeo, Oneguin o Albrecht. Para interpretar hay que ir más allá. Profundizar en las emociones, expresar, comunicar, construir un aura especial de fluencia escénica. Por eso, el bailarín ha de aprender a fluir en el escenario junto con aquello que le toca personificar. Para lograr esa fluencia escénica, este trabajo propone el desarrollo y formación de cuatro cuerpos que han de entrenarse para vivir plenamente la danza. Éstos son: cuerpo físico (mente-cuerpo), cuerpo emocional, cuerpo escénico y cuerpo escindido o "mágico".

Palabras clave: multicorporalidad; personajes; arte escénico; entrenamiento; Estados Unidos.

\section{Four Bodies for Creating Characters in Dance}

\begin{abstract}
Performing a characters in dance, specifically in classical dance, is not just setting a characters such as Juliet, Giselle, or Romeo in motion. To create a character in dance is an entirely different matter. Technical perfection is not enough, the dancer has to go further: become a channel of communication, go deeper into her emotions, to create an auric channel to stage-flow. This way, the person who dances can give shape to what she is personifying through her multicorporality. To accomplish such a process, this work proposes the development and training of four bodies: the physical body (mind-body), the emotional body, the stage body and the split or "magical" body.
\end{abstract}

Keywords: multicorporality; character; performing arts; training; United States. 


\section{Cuatro cuerpos para la construcción de personajes en la danza escénica}

\section{Hacia una comprensión del (los) cuerpo(s) en la danza escénica}

Pienso que si uno no usa su cuerpo, su voz, algún modo de hablar, de caminar y de moverse si no sabe encontrar una forma de caracterizar al personaje que corresponda a la imagen, lo probable es que no pueda transmitir a otros su interior, su espiritu palpitante.

(Konstantín Stanislavski, Creación de un personaje)

El cuerpo [...] no es instrumento, verlo como objeto es desconocer que en él está la esencia de lo humano.

(Domingo Adame, "Cuerpo y transdisciplinariedad: fundamentos para una transpoética escénica")

\footnotetext{
$\mathrm{P}$ ara este trabajo es esencial reflexionar sobre la multiplicidad corporal que el ser humano ha de hacer presente para que el arte de la danza -en todo su esplendor- pueda llegar a desplegarse en escena. Dicha corporalidad se entiende aquí, a la manera de Elka Fediuk y Antonio Prieto Stambaugh, "como un conjunto de prácticas, imaginarios, representaciones y ejercicios de poder que involucran al cuerpo en sus dimensiones físico-biológica, psíquica emocional y socio-cultural, entre otras" (9). De modo que cuando
} 
se estudia al ser que danza no sólo es el cuerpo humano en su nivel físico-biológico lo que hay que tener en cuenta, sino también sus dimensiones emocional y psíquica, sus representaciones socioculturales y sus fuerzas de comunicación e interpretación. La vida misma, en su riqueza tridimensional (individual, social e histórica), no puede quedarse en un solo plano de análisis o de existencia. Tampoco el cuerpo humano. ${ }^{1}$ Esto es precisamente lo que permite proponer la presencia de varios cuerpos para la realidad de la danza escénica, en este caso, para la construcción de personajes en la danza clásica. ${ }^{2}$

En ese sentido, en este trabajo el cuerpo no se entiende como objeto de análisis, tampoco como una bio-estructura mental dicotómica (visión cartesiana), o una dualidad del tipo naturaleza-cultura, razón-pasión o individuo-sociedad. El cuerpo se comprende aquí como un cuerpo multidimensional, un fenómeno vital orgánico y funcional que se vive tanto interna como externamente (el ser y su medio, el ser y su historia). ${ }^{3}$ Sugiere la filosofía de Ortega y Gasset que hay que tener presente que el cuerpo está vivo, es un alma animada, viva, vital, "porque el hombre entero con todo su cuerpo y toda su alma viene a ser un órgano receptivo, viviente antena radiotelegráfica que recoge e intercepta los infinitos temblores de la realidad circundante" (201). La corporalidad del bailarín es, pues, una estructura corporal multidimensional viva, a la vez biológica, expresiva, intelectual, emocional, espiritual y aurática. ${ }^{4}$

1 Para la filosofía de Ortega y Gasset es necesario prepararnos para mirar desde una nueva perspectiva, "de otro modo, no lograremos una verdadera ampliación del orbe. Nuestra cultura superficial nos induce a proyectar todo el universo sobre un sólo plano en vez de respetar delicadamente sus múltiples dimensiones que le proporcionan deleitable, ilimitada concavidad" (141).

2 Aunque este artículo reflexiona con mayor detenimiento en la construcción de personajes para la danza clásica, no se descarta la posibilidad de que lo planteado aquí pueda servir para repensar la actividad interpretativa de la danza escénica en general.

3 El cuerpo es también historia hecha cuerpo. Ya han señalado otros autores que la historia se corporeiza, se hace cuerpo, como lo desarrolló Newman (2003) en su trabajo Embodied History: the Lives of the Poor in Early Philadelphia, en el que revela una relación compleja "entre el cuerpo, la identidad personal y el poder social de las élites". En esa misma línea de trabajo (embodiment-corporeidad) se pueden citar los trabajos de Csordas (2002, 1997 y 1994), autor que se caracteriza por trabajar el cuerpo en términos experienciales desde una perspectiva fenomenológica en la que recupera -principalmente- lo propuesto por Merleau-Ponty y Bourdieu. En la danza también se pueden citar los trabajos de Citro (2009 y 2010), en los que se trabaja sobre cuerpos significantes inspirados sobre todo en la concepción de ser-en-el-mundo de Merleau-Ponty.

4 En consonancia con la teoría propuesta por Walter Benjamin, el aura o dimensión aurática en la representación escénica se refiere al tiempo-espacio en el que se lleva a cabo la escenificación. Por eso el autor dice que "el aura está unida al aquí y ahora, no se puede reproducir. Sobre el escenario, el aura de Macbeth es inseparable, en la mirada del público, del aura del actor que lo representa” (Benjamin 32). 
Comprender la corporalidad en la danza de esta manera proviene de la necesidad teórica de aprehender la realidad humana desde una filosofía en movimiento, una filosofía vital flexible que sea capaz de ver más allá de la pura materialidad presente. Es preciso entender que el cuerpo en la danza es "una entidad de materialidad multisensorial, lúdica, política, erótica e inquietante, susceptible de procurar en el espectador otras maneras de percibir y de relacionarse con quienes le rodean" (Fediuk y Prieto Stambaugh 15). De aquí que hablar de corporalidad danzante sea a la vez referirse a una corporalidad única y presente (el bailarín) y a una corporalidad entrelazada en/con todas sus realidades (audiencia y espacio-tiempo escénico, por señalar las principales). Pues como se afirma en el libro Corporalidades escénicas,

ya no es el cuerpo del actor solamente, sino la disposición de cuerpos en escena compartida [...]. El escenario del teatro es un dispositivo atravesado por otros cuerpos. No sólo el de los actores y espectadores, sino también de objetos y atmósferas logradas gracias al particular manejo del espacio, de los elementos arquitectónicos visuales, la iluminación, el ambiente sonoro, en fin, todos esos elementos que interactúan entre sí, animados por la presencia y acción de cuerpos en la dinámica del acontecimiento (13).

Este trabajo considera, pues, que es sólo a partir de esta multiplicidad en juego -material e inmaterial, individual y compartida- que se hace posible la construcción de personajes en la danza clásica, la aparición de las fuerzas interpretativas del artista en el momento de la escenificación. Traer las fuerzas interpretativas a consideración es importante porque éstas se encargan de dar vida a los personajes o conceptos en la danza, sean príncipes o princesas, faunos, animales antropomorfos o espíritus de otro mundo, como las Willis en Giselle (ver Imagen 1).

Las fuerzas interpretativas van más allá de una ejecución técnica, son aquellas fuerzas que sólo vividas en los actos dancísticos del bailarín cobran vida; en otras palabras, las fuerzas interpretativas son la conjunción de distintas realidades en un individuo donde tienen lugar el movimiento, la música, el ritmo, la iluminación, la escenografía, el escenario, los espectadores, el aire, la gravedad, la levedad, el tiempo, la respiración, la personalidad, el carácter y la sensibilidad (por señalar sólo las principales) [...]. Así, más allá de que el bailarín en su carrera profesional requiere de un aprendizaje óptimo de la antropotécnica, necesita también desarrollar habilidades de expresión y de interpretación, es decir, de crear arte (artistry) con el movimiento, de otra manera parece ser imposible destacar en una compañía dancística o en el escenario mismo (Lay Trigo 49-50). 
INVESTIGACIÓNTEATRAL

Revista de artes escénicas y performatividad

Vol. 12, Núm. 19

abril-septiembre 2021
Cuatro cuerpos para la construcción de personajes en la danza escénica

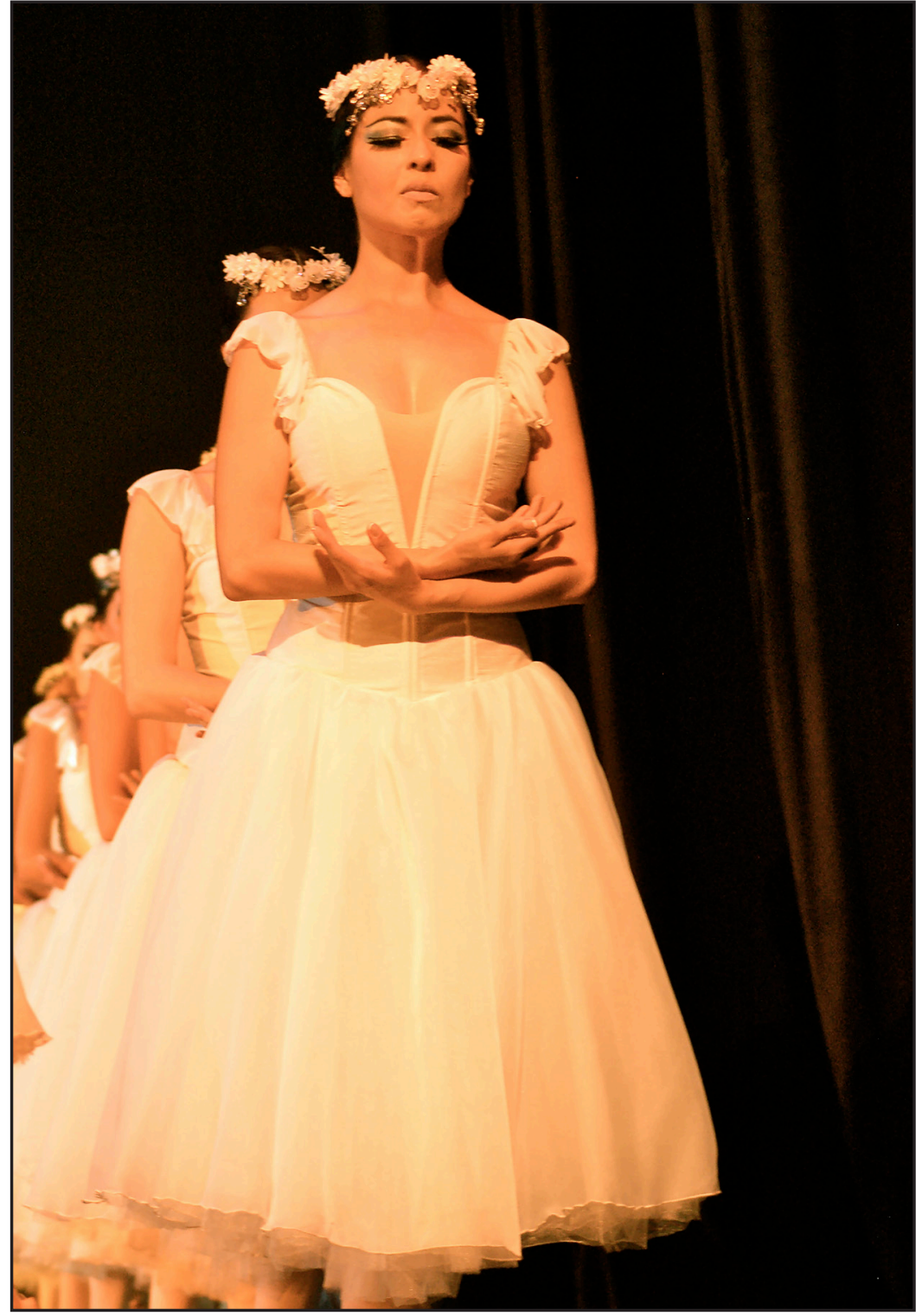

Imagen 1. Las Willis. Segundo acto de Giselle, dirección Carmen Sandoval. Bailarina: Sarahí Lay Trigo. Teatro Galerías, Guadalajara, Jalisco, 2015. Fotografía de Luis A. Ruiz

El cuerpo en la danza escénica tiene, pues, una presencia multidimensional (física-corporal-mental-expresiva-espiritual-aurática) que ha de adquirirse y actualizarse a través del ejercicio cotidiano de la danza. El bailarín ha de entrenar a la par no sólo la técnica, sino además la fuerza interpretativa en y con todos sus cuerpos. Sólo a partir de esa actualización en/con todos sus cuerpos, es que puede llegar a interpretar personajes, historias, conceptos coreográficos, estilos dancísticos. 
Ahora bien, para que el ser que danza pueda desplegar la magia de lo escénico en el momento de su hacer artístico y usar todo el potencial de su constitución multicorporal, este trabajo propone el desarrollo y formación de cuatro cuerpos, cuatro dimensiones del ser.

- Uno, el cuerpo físico (mente-cuerpo). Medio de entrenamiento.

En él están interrelacionados mente y cuerpo en el entrenamiento cotidiano.

- Dos, el cuerpo emocional-expresivo. Medio del hacer escénico.

Con él, el bailarín se adentra en la experimentación de la proyección escénica, en el reconocimiento de sus emociones y en el descubrimiento de su propia energía expresiva: su fuerza interpretativa.

- Tres, el cuerpo teatral-escénico. Medio dialógico.

Es la unidad integradora de mente-cuerpo-emociones-expresión-y-escena. Es esa presencia viva en el escenario que dota al bailarín de una especial plasticidad corporal expresiva. Con esa unidad el bailarín se abre dialógicamente con la audiencia.

- Cuatro, el cuerpo escindido-mágico. Medio de fluencia escénica.

Este último cuerpo es de vital importancia para la vida del bailarín, pues sin él no serían posibles los anteriores. En este trabajo, el cuerpo escindido-mágico se entiende desde dos dimensiones o niveles: el cuerpo escindido-mágico iniciático y el cuerpo escindido-mágico escénico.

Aquí es importante señalar que estos cuerpos han de concebirse siempre como dimensiones de una sola unidad corporal: la corporalidad del ser que danza. Esto es muy significativo porque todo bailarín posee ya la presencia de esta multicorporalidad. Sin embargo, es posible que aún no la haya entrenado en su totalidad, o bien no la haya desplegado hasta su máxima expresión para llegar a su completo dominio. Y aunque en este trabajo los aspectos de esta multicorporalidad han de separarse, esto se hace solamente con el propósito de facilitar su comprensión en el arte de la danza, ya que es sólo a partir de su separación que se facilita el entendimiento de la presencia multicorporal escénica.

Cabe destacar que los cuerpos anteriormente señalados corresponden al resultado de una reflexión decantada a lo largo de más de una década dedicada al estudio y práctica de la danza en el mundo profesional. Se considera que es sólo a partir de la interrelación, balance y amalgamiento de estos cuerpos que el bailarín (formalmente hablando) puede llegar a vivir en su máximo esplendor el arte escénico; es decir, a mover no solamente un cuerpo, sino sus diferentes cuerpos (su multicorporalidad) para danzar, para interpretar, para fluir, para ser presencia aurática, fluencia escénica, aquí y ahora en el momento de escenificación.

Antes de seguir, es necesario señalar que otros autores como Solange Lebourges y Jorge Dubatti ya han concebido la actividad del cuerpo en la danza o en el teatro como la con- 
junción de una multiplicidad de cuerpos. Sin embargo, ambos autores hablan sólo de tres cuerpos. Por un lado, Lebourges (61-63) expone en su libro Lo bailado... nadie me lo quita una concepción tri-corporal para la actividad dancística en la que reconoce como necesarios para la danza tres cuerpos: físico, mental y emocional. Por otro lado, se puede citar la propuesta de Jorge Dubatti desarrollada en su obra Filosofía del Teatro III, donde se reconoce la existencia de una trilogía corporal para el actor en la que interviene el cuerpo natural/social, el cuerpo afectado y el cuerpo poético. Y aunque ambas concepciones fueron importantes para detonar la reflexión teórico-filosófica de este trabajo, éstas no se utilizan aquí. Esto se debe a la separación y significación que cada uno de estos autores otorga a dichos cuerpos.

Así pues, lo que aquí se presenta surge de la vivencia empírica en relación con la teoría. Esto emana de la firme creencia de que es sólo a la luz de esta interrelación teórico-práctica que resulta posible profundizar en el aprendizaje y en la realidad del mundo de la danza. A continuación se desarrollan las concepciones de cada uno de los cuerpos planteados.

\section{El cuerpo físico (mente-cuerpo) como medio de entrenamiento}

Contigo, compañero actor, comparto el privilegio de lo no repetible, de lo único, de la presencia física, pero, ¡cómo te envidio el poder seguir casi hasta la muerte practicando tu pasión! Incluso el paso de los años te hace como a los buenos vinos. Te da cuerpo. [...] Pero la danza es energía y ésta se acaba. Y para conservarla, tengo el compromiso de tomar mi clase cotidiana durante toda mi vida. La clase es el único sésamo de mi danza. (Lebourges 74).

Se inició el culto al cuerpo y tras del culto el cultivo (éste es el orden natural: primero, culto; luego, cultivo. Así aconteció con la agricultura que fue primero un rito y sólo luego una ocupación técnica (Ortega y Gasset 730).

Hay que empezar por decir que la danza es, como la vida misma, un entrenamiento cotidiano, una antropotécnica. ${ }^{5}$ Entendida, esta última, como práctica dinámica y acto constante de ejercitación en el ser humano. El ser humano es, pues -como lo señala Peter Sloterdijk

5 El hábito, la costumbre, la repetición, la práctica, el ejercicio y el entrenamiento son en esencia una antropotécnica. 
en su obra Has de cambiar tu vida-, un ser creador y perfeccionador de antropotécnicas que se forma a sí mismo a través del ejercicio. La realidad humana es en sí misma una constante (la repetición constante del día y la noche, el tiempo). Visto de esta manera, el pulso de la vida tiene como fundamento de humanización la mneme. La virtud del cuerpo vivo es formar hábito, "acumulación de modificaciones pretéritas que reviven en todo momento y operan sobre la actualidad" (177). Por eso se dice que es sólo a partir del ejercicio diario, de la práctica continua, que el bailarín puede re-actualizar la danza en su cuerpo, en su cuerpo físico (mente-cuerpo, dimensión biológica).

El cuerpo físico ${ }^{6}$ así entendido es, entonces, el primer cuerpo con el que el bailarín se enfrenta a su cotidiano andar escénico; con él re-actualiza día a día la técnica, las posiciones, los movimientos, las direcciones, la flexibilidad, la fuerza y el tono muscular (por señalar algunas de las principales herramientas). Ahí el cuerpo físico se re-actualiza en danza y la danza en cuerpo físico. Si el ser quiere danzar tiene que entrenarse. Ésta es la primera dimensión de apropiación de la danza: la apropiación técnica. Primera apropiación de movimiento necesaria, porque la danza es una forma de ejercicio antropotécnico que requiere de un periodo de aprendizaje - a veces largo, a veces más corto- que varía de persona a persona.

Lo mismo sucede en la formación actoral. En ese sentido, Eugenio Barba señala que el actor comienza "en general con la asimilación de un bagaje técnico que se personaliza. El conocimiento de los principios que gobiernan el bios escénico permite algo más: aprender a aprender" (Barba, La canoa de papel 26). ${ }^{7}$ De manera que, para aprender a aprender, tanto en el teatro como en la danza, hay que poner en práctica, en entrenamiento, ese bios escénico (cuerpo-mente).

Según afirma la Theory of Expertise ${ }^{8}$ desarrollada por Anders Ericsson y sus colaboradores, se ha probado que para llegar a ser experto en una actividad humana es necesario un alto grado de entrenamiento físico. El arte escénico no es la excepción. El ex primer bailarín mexicano Jaime Vargas señala al respecto:

6 Aquí la dimensión corporal de lo físico es entendida, más que como una actividad de huesos y músculos, como una actividad corporal-mental en la que están indisolublemente entrelazados mente y cuerpo (sistema inmunitario biológico humano). Todos los seres vienen al mundo con un sistema inmunitario biológico predeterminado (automatizado e independiente) que hay que cuidar y mantener para poder protegerse del exterior, de todo aquello que implica vivir en el mundo. Mente-cuerpo como sistema es el instrumento con el que los seres habitan el mundo.

7 Para profundizar sobre el periodo de aprendizaje en el teatro ver Barba, Eugenio.

8 Ver Ericsson, Anders, Development, The Road To Excellence y The Cambridge Handbook. 
Si haces un movimiento por primera vez el cuerpo no lo conoce, para que un movimiento se convierta en un movimiento primario -quiere decir que ya no tienes que pensar para hacerlo- se necesitan arriba de seis mil repeticiones. Ya que grabas ese movimiento primario se te queda de por vida, si lo grabaste mal se te queda mal, si lo grabaste bien se te queda bien, entonces, antes de que suceda ese proceso tú necesitas repetir, repetir, repetir y mejorar y mejorar y mejorar. En la danza esa repetición la vas cambiando todas las veces para mejorar; ya que mejoraste y llegó al punto en el cual ya está bien, ya está como tú lo quieres, ya nada más lo repites como es [...] por eso es muy importante la repetición, porque necesitas desarrollar esas conexiones que es lo que se llama memoria muscular y, además, ése es el laboratorio en el que vas mejorando (Entrevista).

En ese sentido hay que decir que la primera parte de la formación dancística involucra un ejercicio corporal-mental importante. Uno sin el cual es imposible llegar a dominar el arte de la danza y mucho menos llegar a personificar o caracterizar un personaje en el escenario.

Así, para llegar a ser bailarín de ballet se requiere de la adquisición y dominio de una serie de habilidades físicas-mentales-corporales. Habilidades que van desde el movimiento separado de piernas y brazos, cabeza y torso, hasta el movimiento coordinado y perfectamente musicalizado de todo el cuerpo. El grado de relación, interrelación o balance entre separación y coordinación depende del estilo, escuela o técnica en la que el bailarín se esté formando. Hasta aquí queda claro que el ejercicio importa mucho, digamos que es lo único que puede facilitar un camino -más o menos seguro- para alcanzar el dominio antropotécnico en el arte de la danza clásica.

Sin embargo, para ser bailarín en un arte como el de la danza clásica, no basta con lograr el dominio físico corporal, eso sería simplemente la adquisición de una antropotécnica. Y como la danza no es sólo técnica o ejercicio, sino que también es arte, el bailarín ha de ir más allá. Jerzy Grotowski afirma que "el arte es una evolución, un estado de madurez, una elevación que nos permite emerger de la oscuridad a la luz" (215). En sintonía, la danza ha de elevarse para alcanzar el nivel de arte, madurar, salir de la oscuridad para alcanzar su luminosidad. Salir de la oscuridad técnica para llegar a la luminosidad expresiva. En otras palabras, no se trata sólo de entrenar el cuerpo sino de sentirlo. Ir de lo emocional a lo expresivo. Ir de abajo hacia arriba, de atrás hacia delante. Girar, brincar, alternarse, unirse, desunirse. Ir del cuerpo físico que está arraigado al suelo, al cuerpo emocional-expresivo que es pura luminiscencia. 


\title{
III. El cuerpo emocional-expresivo como medio del hacer escénico
}

\begin{abstract}
Aprende, vive la anatomía íntimamente, desde sus tendones, sus tripas, su columna vertebral. Piensa esqueléticamente, muscularmente, visceralmente en un viaje silencioso y perseverante. Al final, son mis sentimientos, mis emociones, los que van a ocupar y a enriquecer el trabajo a través de una elaboración, un refinamiento, una intencionalidad. Van a darle sentido y a proyectar la obra (Lebourges 62).
\end{abstract}

Es preciso, ante todo, que el actor deje de ser lo que es hoy, mero realizador de una obra escrita, y se convierta en otra cosa; mejor dicho, en mil cosas: acróbata, danzarín, mimo, juglar, haciendo de su cuerpo elástico una metáfora universal (Ortega y Gasset 327).

Es difícil señalar o definir a ciencia cierta en qué momento el bailarín comienza a expandir su movimiento, su conocimiento, su dominio de la danza como técnica, para comenzar a profundizar en ese autoconocimiento elástico de las emociones, en esa dimensión de lo expresivo, metáfora universal de las fuerzas interpretativas. Ir de una primera dimensión corporal a una segunda. Sin embargo, en toda trayectoria formativa escénica para la danza es necesario ese movimiento de expansión ${ }^{9}$ de lo técnico a lo expresivo. Sin esa expansión el bailarín se queda solamente en el nivel de la antropotécnica. A continuación, se presenta el testimonio del ex primer bailarín Jaime Vargas, quien afirma que el personaje que lo llevó de la mano en este proceso de expansión se llama El hombre atormentado, de la obra Carmina Burana:

El hombre atormentado fue como mi despertar artístico, y lo seguí creciendo. Después de esto ya empezaba a entender cómo desarrollar otros personajes que tenían contenido emocional fuerte. Esta parte fue muy importante porque me abrió una nueva rama en la que no estaba muy metido y que es pilar de lo que uno hace como artista, como bailarín, y que te hace madurar. Gracias a esto también empecé a hacer otros roles en los cuales no me veían. A mí desde el principio me catalogaron como si fuera príncipe. A veces te catalogan, o te etiquetan con un cierto tipo de personaje. Por ejemplo, esta persona es el príncipe, este es el malo, este es... Entonces yo estaba dentro de ese rango [el de ser príncipe], de modo que todo lo que hacía en mis primeros años de carrera eran cosas de príncipe y cosas así. Que también me encantaban, pero a mí también me gustaban las cosas más fuertes; este rol [El hom-

9 Para profundizar en el tema de las trayectorias formativas ver Lay Trigo. 
bre atormentado] fue uno de ellos. Ya después de interpretar este rol se vio que yo podía ser más versátil y entonces empecé a tener otra gama diferente de trabajo que me encantó hacer, por ejemplo, pude hacer no sólo Romeo, sino también Oneguin, el bueno y el malo del cuento (Entrevista).

Es por eso que es necesario que el bailarín vaya más allá de la técnica y se aventure a experimentar papeles interpretativos de un carácter emocional más fuerte, que lo ayuden a vivir otro tipo de calor emocional, otra temperatura energética, otra calidad interpretativa. Quedarse sólo en el nivel de la antropotécnica es habitar un lugar frío en el que la danza solamente es movimiento sin dirección, sin intención, sin personificación, sin posibilidad de exploración interpretativa emocional-expresiva.

Para evitar estancarse en la actuación técnica, mecanicista, es necesario encontrarle un sentido al movimiento, un propósito, un objetivo expresivo. Ir a su esencia. Ir de adentro hacia fuera y viceversa. Ir del cuerpo físico a la emoción y de la emoción al movimiento. Ir del movimiento del bios físico al movimiento expresivo del bios del alma. O como señala Eugenio Barba, del animus al anima:

El primer paso consiste en la percepción de la existencia de dos polos, uno vigoroso, fuerte (Animus), y otro suave, delicado (Anima), dos temperaturas distintas, que nos tientan a confundirlas con la polaridad de los sexos. [...]. Energía-Anima (suave) y energía-Animus (vigorosa) son términos que [...] puntualizan una polaridad pertinente a la anatomía del teatro, difícil de definir por palabras y por ende, difícil de analizar, desarrollar y transmitir. Y sin embargo, es de esta polaridad y del modo en que el actor llega a dilatar su campo que dependen sus posibilidades de no cristalizarse en una técnica más fuerte que él (La canoa de papel 99-100).

Y ahí va el bailarían, experimentando un ir y venir entre lo suave y lo vigoroso. Entre lo dinámico y lo pasivo. Entre lo expresivo y lo puramente técnico. Entre la emoción y el movimiento. Entre la técnica y la fuerza interpretativa. Se puede decir que el bailarín comienza a experimentar una especie de duplicidad. Es uno en-y-con su cuerpo físico. Es dos, en-ycon su cuerpo emocional-expresivo. Un bailarín (un ser), dos dimensiones, dos cuerpos, dos energías. El bailarín se convierte a la vez en un bailarín técnico afectivo, o bien, en un atleta afectivo -señalaría Artaud (1964)-. Y en ese mundo de lo afectivo, de lo emocional, hay que decir que la emoción se convierte a la vez en, "evaluación, interpretación, expresión, significación, relación, regulación de un intercambio; se modifica según los públicos y el contexto; difiere en su intensidad y aun en sus manifestaciones, de acuerdo con la singularidad personal" (Le Breton 191-192). 
Por eso es tan importante que el bailarín haga ese paso expansivo en su formación dancística. Sin lo emotivo no tiene posibilidad real de darle vida a la interpretación ni de construir un personaje, pues el contexto escénico-teatral pierde o carece de toda calidez, de vivacidad, de esencia. Es decir, carece de todo aquello que se quiere contar, comunicar. Carece de sus historias, sus personajes, sus sensaciones, sus emociones. Dicho de otra manera, con el cuerpo físico el bailarín puede hacer mucho visualmente en el escenario; sin embargo, sin expresividad, no hay comunicación, no hay nada que interpretar.

Si en el bailarín prevalece sólo el cuerpo o la dimensión de la técnica, éste no logra transmitir realmente nada emotivo, sólo la forma. Queda así que ese cuerpo sólo puede atraer la mirada de lo cotidiano, pero no logra penetrar en ella para redirigirla, para llevarla hacia la mirada extra-cotidiana, extraordinaria. Ahí la danza solo puede ser forma y no fondo. Pero como la danza es a la vez forma y fondo, el cuerpo emocional es una facultad esencial para el arte de la danza.

Es por eso que el bailarín ha de aprender y experimentar el cuerpo emocional-expresivo. Ir de uno a otro. Quedarse dentro (en la técnica) y salir (con proyección escénica y fuerza interpretativa). Con el tiempo el ser que danza aprende a unir ambos cuerpos (físico y emocional). Sólo así es posible unir lo técnico con lo emotivo para ir más allá y experimentar lo que es el cuerpo escénico, el cuerpo teatral.

\section{El cuerpo teatral-escénico como medio dialógico}

Si en la vida real es menester el proceso correcto y continuado de la comunicación, en la escena lo es diez veces más. Esto deriva de que la naturaleza del teatro se basa en la comunicación de los personajes entre sí, y de cada uno consigo mismo. En efecto, supongan que el autor presenta dormidos a sus héroes o en estado de inconsciencia [...]. En tales circunstancias no hay motivo para que el espectador acuda al teatro, puesto que no se le ofrece lo que ha venido a buscar, es decir, sentir las emociones y descubrir las ideas de los personajes que intervienen en la obra (Stanislavski 252).

El cuerpo es sólo la mitad del ser viviente: su otra mitad son los objetos que para él existen, que le incitan a moverse, a vivir (Ortega y Gasset 298).

Una vez abordados el cuerpo físico y el cuerpo emocional-expresivo, es momento de pasar a la siguiente dimensión corporal: el cuerpo escénico o cuerpo teatral, que no es más que la proyección del perfecto amalgamiento construido entre cuerpo físico y emocional-expresivo. Es decir, aflora cuando el ser que danza logra dejar de pensar en la técnica 
(el hacer de la danza como ejecución) y se olvida de lo que tiene que comunicar expresivamente (el decir de la danza como forma de expresión, de interpretación) para finalmente fluir en escena (la persona logra convertirse en danza). Alcanzar su otra mitad desde la visión orteguiana, que no son sólo objetos, sino también espacios, tiempos y seres. Ahí el artista fluye, fluye con el movimiento. Fluir en el escenario es fundamental. Convertirse en canal de diálogo, de comunicación, de goce estético ${ }^{10}$ entre lo que sucede en el escenario y la audiencia (la cuarta pared). De otra manera el canal de apertura dialógica entre la dimensión escénica (la realidad del bailarín) y la cuarta dimensión (la realidad que vive el público) no es posible.

En ese sentido, la apertura comunicativa ha de estar constituida por un canal de dos puntas incesantes de comunicación (inicio-llegada): el bailarín y la audiencia. Dos puntas que van del movimiento y creación del bailarín (apertura por acción hecha movimiento y emociones), hacia la apertura por aprehensión (la audiencia aprehendiendo la realidad a través de sus sentidos). Con esto es posible decir que la comunicación comienza sólo a partir de que estas condiciones estén dadas. Sin dicho canal de comunicación el movimiento y la expresión, la danza y sus fuerzas interpretativas no tienen punto de llegada.

Si se aprende a manejar este cuerpo teatral-escénico como canal comunicativo, la danza lograr fluir naturalmente, se convierte en canal de fluencia en el que el movimiento, las emociones, las fuerzas interpretativas, acontecen como fuente dialógica de comunicación. Así, cuando se fluye en el escenario se logra, finalmente, transmutar/transformar el cuerpo, los cuerpos, convertirse formalmente en bailarín y llegar a liberar esa realidad escénica interpretativa sin límites. Esto es, superar los fundamentos técnicos y expresivos para lograr un balance que sirva a un objetivo mayor: la comunicación dialógica, energética, aurática y termotópica ${ }^{11}$ (un espacio atemperado y cálido de comunicación y diálogo) entre bailarín y público, entre bailarín y escena.

El balance es la clave aquí. Sin embargo, para lograr ese equilibrio no es suficiente armonizar la habilidad física con la expresiva. Para lograr armonía entre ambas dimensiones es necesario también controlar la fuerza, las tensiones internas y externas (conscientes e inconscientes), físicas, biológicas y emocionales. En pocas palabras, aprender a

10 "El goce estético (rasa, en sánscrito), se produce cuando el realizador es capaz de evocar un complejo repertorio de emociones y comunicarlas al espectador" (Fediuk y Prieto Stambaugh 17).

11 En esta parte se retoma tan sólo un concepto de la filosofía antropogénica de Peter Sloterdijk, quien señala en su obra Esferas III, que la realidad humana ha de ser un espacio cálido, lleno de confort. A ese espacio térmico desde la filosofía sloterdijkeana se le denomina termotopo. Ahí los seres humanos se relacionan de acuerdo a las conexiones satisfactorias que les genera ser parte de ese espacio de convivencia (306). 
controlarse a sí mismo, emprender el viaje del autoconocimiento. Pues como señala Erick Hawkins, "la función primaria del arte es el viaje de descubrimiento o el movimiento en y para sí mismo. El hecho mágico de la existencia todavía está esperando a los bailarines que harán ese viaje" $(21) .^{12}$

Es preciso, pues, que la actividad dancística se comprenda también como una vía para el conocimiento profundo de sí mismo. Si no se emprende ese viaje de autoconocimiento, si no se logra ese balance entre lo técnico y lo expresivo, entre "lo consciente y lo inconsciente de la psique individual [...], uno u otro dominará al ser y éste se encontrará dentro de una guerra civil interna" (Hawkins 1 ). ${ }^{13}$ Por eso es tan importante que el bailarín encuentre un balance entre cuerpo, mente y emociones.

He aquí una verdadera muestra del poder de lo formativo en el individuo, poder que sólo puede surgir cuando el ser se atreve a romper con el pacto de lo inercial [...]. El artista del movimiento que quiere llegar al lugar de las primeras figuras ha de atreverse a desafiar la formación de semejanza y homogeneidad en la que ha vivido a lo largo de su trayectoria para encontrarse consigo mismo, con su propio modo de vivir la danza. Si no logra esa unión, esa acción de re-ligarse en el que puede vivir con plena libertad su modo de ser danza, es muy difícil que logre destacar (Lay Trigo 522).

Esto es así porque el artista no puede surgir sin previo, profundo y consciente trabajo sobre sí mismo. Sin autoconocimiento no hay actor, señalaría Konstantín Stanislavski en El trabajo del actor sobre sí mismo. O siguiendo a Jerzy Grotowski en Hacia un teatro pobre, sin autopenetración, sin autoentrega, no hay actor. Por lo tanto, entendido el bailarín también como actor (bailarín-actor), sin autoconocimiento y trabajo sobre sí mismo tampoco hay bailarín. Esto sin duda requiere de tiempo y dedicación. Si el bailarín quiere llegar a vivir con plenitud el arte de la danza, ha de dedicarse con devoción a su entrenamiento, a su propio conocimiento, a su propia indagación íntima, a esa autopenetración.

Para ello el bailarín ha de mantener bien delimitadas sus tracciones corporales, el movimiento de sus músculos, la tonalidad de sus sentimientos, el talante de sus emociones, la fuerza de sus impulsos. Es sólo conociéndolos que será capaz de dejarlos salir en el momento exacto y lograr la perfecta mesura entre cuerpo físico y cuerpo emocional-expresi-

12 The primary function of art, or movement in and for itself, in the magical pure fact of existence, is still awaiting those dancers who will make that trip.

13 The conscious and unconscious of the individual psyche [...], one or the other being over-dominant and top-heavy, you find an inner civil war 
vo. Después, sólo después, podrá dar entrada al cuerpo teatral-escénico y hacer posible la acción dialógica con el público.

Por eso, el cuerpo teatral-escénico ha de entenderse a la vez como un doble acto, un acto de armonización y un acto de apertura. El sujeto que danza se armoniza a sí mismo para abrirse con los otros. Sin dicho acto doble de armonización y apertura no es posible la transmisión dialógica en el escenario. Esta dupla es necesaria para articular y favorecer la comunicación escénica. Sólo así la persona ha de poder entrar y salir de sí misma para dialogar con el escenario de lo humano, con el espacio que habita y con los seres que se encuentran en él.

Una vez integrado cuerpo físico y cuerpo emocional-expresivo, el bailarín ha de querer ir más allá de la mirada extra-cotidiana para lograr que aparezca en el escenario la poíesis, la mirada poética, la mirada extraordinaria, el cuerpo escindido-mágico. Pura poesía mágica en movimiento. Ahora bien, para lograr la aparición de este cuerpo teatral-escénico mágico, el bailarín primero tiene que estar decidido, dispuesto, escindido de lo cotidiano. Pues sólo a partir de la decisión de escindirse es que se puede entrar en el laboratorio de experimentación que constituye esta práctica, entre actividad de entrenamiento, actividad expresiva y vida activa en el escenario. Aquí es donde entra el cuarto cuerpo, el cuerpo escindido-mágico. El cuarto que podría ser el primero, pues sin este movimiento de separación hacia la danza, hacia lo escénico, el bailarín simplemente no podría ser.

\section{v. El cuerpo escindido-mágico como fluencia escénica}

En muchas lenguas existe una expresión que podría escogerse para condenar lo que es esencial para la vida del actor. Es una expresión gramaticalmente paradójica, en la que una forma pasiva llega a asumir un significado activo [...] No es una expresión ambigua sino hermafrodita, combinando acción y pasión [...]. Se dice, efectivamente, "estar decidido", "essere deciso", "être décide", "to be decided". [...] "Decidir" quiere decir, etimológicamente, "cortar" (Barba, El arte secreto del actor 30-31).

El cuadro, como la poesía o como la música, como toda obra de arte, es una abertura de irrealidad que se abre mágicamente en nuestro contorno real [...]. Es la obra de arte una isla imaginaria que flota rodeada de realidad por todas partes. Para que se produzca, es, pues, necesario que el cuerpo estético quede aislado del contorno vital (Ortega y Gasset 310-311). 
Como circunvalan las citas anteriores, cortar, decidirse, aislarse, escindirse es esencial para la vida escénica. Sin ese acto de escisión es imposible dedicarse al mundo de la danza, al mundo escénico, al mundo de la magia escénica. De manera que sólo se puede edificar el individuo como artista de lo escénico mediante un corte de separación. Separación que lo lleve a una unión: escisión del mundo de lo cotidiano y unión al mundo de lo extraordinario. Escisión de la vida diaria, unión a la vida poética del escenario. Corte de lo mundano para unirse al mundo de la disciplina, de la voluntad, del ejercicio y del entrenamiento. Unión con el mundo de la magia: el escenario. Sólo así es posible hacerse en y con el arte de la danza.

Y es que sólo cuando un artista se decide a comenzar, cuando se abre a su destino en el arte, es cuando aparece claramente su finalidad. Es ahí cuando el bailarín decide a formarse a través del ejercicio, "por la ascesis, la exigencia sin aproximaciones ni subterfugios que en esta profesión no perdonan, mente obstinada en perseguir su fin" (Lebourges 59). Con la ascesis puesta en el bailarín y la meta en la danza, es que se puede comenzar a experimentar el laboratorio de lo humano en la danza. Laboratorio que necesariamente ha de estar lejos de la cotidianeidad del artista, del mundo exterior. Cuanto más el bailarín entre en un acto de ascesis y secesión (separación), más posibilidades tiene de encontrar su magia, la magia del arte de la danza.

Pero para crear apertura mágica hacia lo escénico, no basta sólo con el entrenamiento en un espacio distanciado de lo cotidiano, con balancear mente, cuerpo y emociones. Hay que ir más allá. Ir hacia otro nivel de escisión para que aparezca lo mágico. Ahí el corte ha de ser entendido desde dos niveles. Un corte de escisión doble, por así decirlo. Primero, un corte de acto iniciático, y segundo, un corte de escisión escénico.

Corte de acto iniciático. Además de la escisión espacio-temporal que tiene que hacer la persona con el mundo de lo cotidiano para dedicarse al laboratorio disciplinario de experimentación humana que es la danza, el individuo ha de querer, con decisión y firmeza, iniciarse en el mundo de la danza. De otra manera no es posible adentrarse en el conocimiento de esa diversidad de cuerpos que son necesarios para danzar. De modo que el ser empieza realmente a experimentar su formación en el arte de la danza cuando decide iniciarse conscientemente en esta práctica humana. "Filosóficamente hablando, la iniciación equivale a una mutación ontológica del régimen existencial. Al final de las pruebas, goza el neófito de una vida totalmente diferente de la anterior a la iniciación: se ha convertido en otro" (Eliade 8). Con este acto de iniciación el bailarín comienza un renacimiento en, con y para la danza.

Segundo, el corte de escisión escénico. Este segundo momento se refiere a la escisión necesaria que el artista ha de hacer al momento de entrar en el escenario. Ese es el nivel o la dimensión del cuerpo mágico, del cuerpo alquímico. Cuerpo que se refiere al momento escénico en el que el individuo ha de dejar de lado sus problemas, su tiempo personal, su vida social, sus preocupaciones, su cotidiana realidad para sólo adentrarse en el tiempo escénico, el tiempo de lo extraordinario, de la magia. El artista ha de entregarse a su acción artística y fluir con ella, 
"cuando ello sucede, se identifica con ella de una manera creadora. Pero en cuanto se distrae, cae nuevamente bajo el dominio de su propia vida personal" (Stanislavski 251-252).

Aquí el bailarín ha de estar pendiente de que ese corte, entre el momento escénico y su vida personal, sea posible. Ya que, para poder fluir en el escenario, el bailarín ha de hacer un corte espacio-temporal con su realidad humana (su vida cotidiana); sólo así es posible abrirse a la fluencia energética que se vive en el escenario. En esta escisión la persona ha de dejarse fluir, prestar su cuerpo - mejor dicho, sus cuerpos- en función del arte dancístico para poder convertirse en ese cuerpo-teatral-escénico-mágico.

El corte de escisión escénico se convierte también en un corte de discernimiento. Hay que tener presente, como señala Stanislavski, que:

lo repulsivo no crea lo bello; el cuervo no engendra la paloma; la ortiga no nos da rosas. Por consiguiente, no toda verdad que conocemos en la vida es buena para el teatro. La verdad en la escena debe ser auténtica, pero estar embellecida, depurada de los pormenores superfluos de la vida corriente. Tiene que ser realmente veraz, pero con la carga poética de la imaginación creadora; que sea realista, pero que esté dentro del arte y que nos eleve (210).

En suma, la magia escénica aparece a partir de tres momentos o condiciones. Uno, el amalgamiento entre cuerpo físico y emocional-expresivo (amalgamiento entre primer y segundo cuerpo). Dos, la fluencia, ese canal de energía dialógica que acontece en el escenario (tercer cuerpo). Tres, la aparición de la escisión en la vida del bailarín, escisión doble que le permitirá tomar las riendas del tiempo-espacio teatral (cuarto cuerpo). Pues como Grotowski señala, para el teatro, el bailarín ha de entregarse totalmente en "una técnica del 'trance' y de la integración de todas las potencias psíquicas y corporales del actor, que emergen de las capas más íntimas de su ser y de su instinto, y que surgen en una especie de 'transiluminación"' (11). Solo a partir de la entrega total es que se pueden conocer las capacidades escénicas que encierra la multicorporalidad del bailarín. Pues como señala Ortega y Gasset, para la ciencia, "las ideas científicas actúan sobre las almas no científicamente, sino mágicamente" (371). Así también lo hace la danza. La danza actúa sobre las almas no técnica ni artísticamente, sino mágicamente.

\section{Reflexiones finales}

Después de la exposición de esta cuádruple corporalidad del bailarín, únicamente queda señalar que la danza no es sólo "una forma de arte humana que ha pasado de cuerpo a 
cuerpo, de mente a mente" (Villela y Kaplan 299), sino también de emoción a emoción y de escisión en escisión, hasta llegar a la magia escénica en la que el movimiento y la fuerza interpretativa se fusionan para dar entrada a la acción dialógica mágica creadora.

Esto es así porque el bailarín ha de trabajar en/con la multiplicidad de cuerpos que lo constituyen para poder adentrarse con mayor profundidad en su arte, en este caso en el arte de la danza clásica y la construcción de sus personajes. Sólo a partir del manejo de esos cuerpos es que el bailarín puede entrar en carácter. Carácter de personaje, carácter de estilo, carácter de movimiento, carácter de emoción, carácter de proyección escénica, carácter interpretativo, carácter de mago. Carácter para hacer y crear magia en el escenario.

Desde la perspectiva de este estudio, sin esa estructura corporal coordinada y dirigida por el bailarín en la que están balanceándose activamente cuerpo físico (cuerpo-mente), cuerpo emocional-expresivo, cuerpo escénico teatral y cuerpo escindido-mágico, no es posible llegar a ser un artista de la danza en todo su esplendor.

Poner en acción estas cuatro dimensiones en escena, estos cuatro cuerpos del ser que danza, no es tarea fácil. El mayor reto está en el bailarín mismo. Todo depende de los modos en los que la persona logre encontrarse a sí misma en esa multicorporalidad que forma parte de la danza. Para lograrlo es esencial que el ser que danza se atreva a profundizar más allá de la técnica para llegar al encuentro con la vida misma, con la magia de sí mismo. La vida ha de servir, pues, como fuente de inspiración. Porque, como señala Grotowski, para los actores, el ser que actúa -en este caso, el bailarín- "no interpreta a su personaje, sino que va a llevar a cabo un acto con todo su ser, un acto que es una respuesta general al desafío planteado por la obra, por el personaje y por su propia vida y experiencia" (225).

Es sólo a partir de la entrega total, del entrenamiento escénico, del ir y venir de cuerpos, del balance entre lo interno y externo, de la atemperación energética, emocional, física e interpretativa que se puede lograr el dominio de esa multicorporalidad, y con ello adentrarse en la magia que es la danza en el escenario. Encontrar la magia más temprano que tarde, depende sólo del individuo que danza y de su propio laboratorio de experimentación y autoconocimiento.

\section{Fuentes consultadas}

Artaud, Antonin. El teatro y su doble. Buenos Aires: Sudamericana, 1964. Barba, Eugenio. El arte secreto del actor. Ciudad de México: Pórtico, 1990.

Barba, Eugenio. La canoa de papel. Tratado de antropología teatral. Buenos Aires: Catálogos, 1994. 
Barba, Eugenio. Más allá de las islas flotantes. Ciudad de México: Gaceta, 1986.

Benjamin, Walter. La obra de arte en la época de su reproducción mecánica. Madrid: Casimiro, 2018.

Citro, Silvia (coord.). Cuerpos plurales. Antropología de y desde los cuerpos. Buenos Aires: Biblos, 2010.

Citro, Silvia (coord.). Cuerpos significantes. Travesías de una etnografía dialéctica. Buenos Aires: Biblos, 2009.

Csordas, Thomas. J. Body, Meaning, Healing. New York: Palgrave Macmillan, 2002.

Csordas, Thomas. J. The Sacred Self. A Cultural Phenomenology of Charismatic Healing. California: University of California, 1997.

Csordas, Thomas. J. (ed.). Embodiment and Experience. The Existential Ground of Culture and Self. New York: Cambridge University, 1994.

Dubatti, Jorge. Filosofía del Teatro III. El teatro de los muertos. Buenos Aires: Atuel, 2014.

Eliade, Mircea. Muerte e iniciaciones místicas. Buenos Aires: Terramar, 2008.

Ericsson, Anders (ed.). Development of Professional Expertise. Toward Measurement of Expert Performance and Design of Optimal Learning Environments. UK: Cambridge University, 2009.

Ericsson, Anders (ed.). The Road To Excellence: The Acquisition of Expert Performance in the Arts and Sciences, Sports and Games. New Jersey: Lawrence Erlbaum, 1996.

Ericsson, Anders, et al. The Cambridge Handbook of Expertise and Expert Performance. UK: Cambridge University Press, 2006.

Fediuk, Elka y Antonio Prieto Stambaugh, editores. Corporalidades escénicas. Representaciones del cuerpo en el teatro, la danza y el performance. Xalapa: Universidad Veracruzana, 2016.

Grotowski, Jerzy. Hacia un teatro pobre. Ciudad de México: Siglo xxi, 2004.

Hawkins, Erick. The Body is a Clear Place and Other Statements of Dance. Pennington: Dance Horizons Book, 1992.

Lay Trigo, Sarahí. Ser danza. Trayectorias formativas en el arte de la danza. Tesis de doctorado en Educación, Universidad de Guadalajara, 2018.

Le Breton, David. Las pasiones ordinarias. Antropología de las emociones. Buenos Aires: Nueva Visión, 1999.

Lebourges, Solange. Lo bailado... Nadie me lo quita. Memorias de una bailarina. Ciudad de México: Conaculta, 2009.

Newman, Simon P. Embodied History. The Lives of the Poor in the Early Philadelphia. Philadelphia: University of Pennsylvania, 2003.

Ortega y Gasset, José. Obras completas. Tomo II. El Espectador. Madrid: Revista de Occidente, 1963. 
INVESTIGACIÓNTEATRAL

Revista de artes escénicas y performatividad

Vol. 12, Núm. 19

abril-septiembre 2021
Cuatro cuerpos para la construcción

de personajes en la danza escénica

Sarahí Lay Trigo

Sloterdijk, Peter. Has de cambiar tu vida. Sobre antropotécnicas. Valencia: Pre-Textos, 2012.

Sloterdijk, Peter. Esferas III. Madrid: Siruela, 2006.

Stanislavski, Konstantín. El trabajo del actor sobre sí mismo en el proceso creador de la vivencia. Barcelona: Alba, 2007.

Vargas, Jaime. Entrevista personal. 2 de octubre de 2015.

Villella, Edward y Larry Kaplan. Prodigal Son: Dancing for Balanchine in a World of Pain and Magic. Pittsburgh: University of Pittsburgh Press, 1998. 